Check for updates

Cite this: RSC Adv., 2018, 8, 16061

\title{
Morphology and mechanical behavior of diamond films fabricated by IH-MPCVD
}

\author{
Rong Tu, (D) a Tiantian Xu, (D) a Dengfeng Li, ${ }^{a}$ Song Zhang, *a Meijun Yang, ${ }^{a}$ Qizhong Li, ${ }^{b}$ \\ Lianmeng Zhang, ${ }^{a}$ Toshihiro Shimada, (D) ac Takashi Goto ${ }^{\text {ad }}$ and Ji Shia \\ Morphology of diamond films has been controlled via intermediate frequency induction heated microwave \\ plasma chemical vapor deposition (IH-MPCVD), which was transformed with various substrate \\ temperatures $\left(T_{\text {sub }}=923-1123 \mathrm{~K}\right)$ and $\mathrm{CH}_{4} / \mathrm{H}_{2}$ ratios $\left(\eta_{\mathrm{c}}=0.5-2\right.$ vol\%). The coupling effects of $T_{\text {sub }}$ and \\ $\eta_{\mathrm{c}}$ on the structure of diamond films have been studied. At $\eta_{\mathrm{c}}=0.5 \mathrm{vol} \%$, the $\mathrm{sp}^{3} / \mathrm{sp}^{2}$ ratio of diamond \\ films reached $98 \%$ at $1073 \mathrm{~K}$, surface roughness $\left(R_{\mathrm{ms}}\right)$ increased from 50 to $85 \mathrm{~nm}$ with increasing $T_{\text {sub. }}$ \\ the maximum hardness $\left(H_{\mathrm{a}}\right)$ reached $84 \mathrm{GPa}$ at $973 \mathrm{~K}$, and the maximum Young's modulus $(E)$ reached \\ $642 \mathrm{GPa}$ at $1023 \mathrm{~K}$. The residual stress $(\sigma)$ was calculated as a function of $T_{\text {sub }}$ and $\eta_{\mathrm{c}}$. The quality factor \\ $(Q)$, combining microstructure and mechanical behavior, has been creatively defined to evaluate the \\ quality of diamond films.
}

Received 3rd March 2018 Accepted 24th April 2018

DOI: 10.1039/c8ra01871e

rsc.li/rsc-advances

Besides, substrate temperature $\left(T_{\text {sub }}\right)$ plays an important role

\section{Introduction}

Chemical vapor deposited (CVD) diamond covers a broad range of synthetic diamond materials with great variety of properties such as high hardness, high elastic modulus, chemical inertness, and low self-friction coefficient. ${ }^{1-4}$ CVD diamond can be broadly divided into two grades, i.e., microcrystalline diamond (MCD) and nanocrystalline diamond (NCD), with the crystallites in the micron size range and smaller than $500 \mathrm{~nm}$, respectively. ${ }^{5}$ NCD films are highly desirable for the substrates of MEMS (Micro-Electro-Mechanical Systems) because the smaller grain size insures a smoother surface for the devices above comparing with MCD. ${ }^{6-8}$ However, the mechanical properties of NCD, such as hardness and elastic modulus, are lower than those of conventional MCD due to the presence of $\mathrm{sp}^{2}$ non-diamond species. ${ }^{9}$ Therefore, the smooth surface, good mechanical property and high $\mathrm{sp}^{3} / \mathrm{sp}^{2}$ ratio are usually difficult to obtain simultaneously, and it is hard to evaluate the quality of diamond-related materials only according to their individual properties. Here, we define quality factor $(Q)$, combining microstructure and mechanical behavior to evaluate the deposits.

\footnotetext{
${ }^{a}$ State Key Laboratory of Advanced Technology for Materials Synthesis and Processing, Wuhan University of Technology, 122 Luoshi Road, Wuhan 430070, People's Republic of China.E-mail: kobe@whut.edu.cn; superkobe0104@gmail.com

${ }^{b}$ Hubei Key Laboratory Advanced Technology of Automobile Parts, Wuhan University of Technology, 122 Luoshi Road, Wuhan 430070, People's Republic of China ${ }^{c}$ Division of Applied Chemistry, Hokkaido University, Sapporo 060-0808, Japan ${ }^{d}$ Institute for Materials Research, Tohoku University, 2-1-1 Katahira, Aoba-ku, Sendai 980-8577, Japan

eJapan Department of Metallurgy and Ceramics Science, Tokyo Institute of Technology, Tokyo 152-8552, Japan
} in growth process of diamond. Not only the structure and properties of CVD diamond films, but also the growth rate is mainly influenced by $T_{\text {sub }}$. For example, the commonly low $T_{\text {sub }}$ may hinder the formation of strong chemical bonds between atoms, while the high temperature may enhance the graphite species. ${ }^{\mathbf{1 0}}$ However, it is difficult to control precisely the $T_{\text {sub }}$ in MPCVD system because the $T_{\text {sub }}$ is attributed to several factors, e.g., discharging plasma density and substrate location, which is influenced strongly by the microwave power $\left(p_{\mathrm{w}}\right)$. Moreover, $T_{\text {sub }}$ would certainly decrease due to the heat exchange between the chamber and external environment. And it is hard to increase the decreased $T_{\text {sub }}$ by adjusting $p_{\mathrm{w}}$ due to its strong influence on $T_{\text {sub }}$. In general, $T_{\text {sub }}$ is difficult to be precisely controlled only through the adjustment of $p_{\mathrm{w}}$, which resulting in the difficulty of researches on diamond structures.

In this study, an IH-MPCVD apparatus was developed to fabricate diamond films. The $T_{\text {sub }}$ was compensated with an intermediate frequency induction heating system by selfadjusting the $\mathrm{IH}$ power $\left(p_{\mathrm{h}}\right)$ according to the thermocouple that set under the substrate. The effects of $\mathrm{CH}_{4} / \mathrm{H}_{2}$ ratio and deposition temperature on the morphology, quality factor $(Q)$ and deposition rate of the diamond films has been investigated, and the growth mechanism of these films was also proposed.

\section{Experimental}

Fig. 1 shows the experimental schematic of the home-made induction heated microwave plasma CVD (IH-MPCVD). The system consisted of a microwave generator network (MPS-15D, NISSIN, Tokyo, Japan, $2.45 \mathrm{GHz}, 1.5 \mathrm{~kW}$ ), a quartz tube chamber, an intermediate frequency induction heating device 


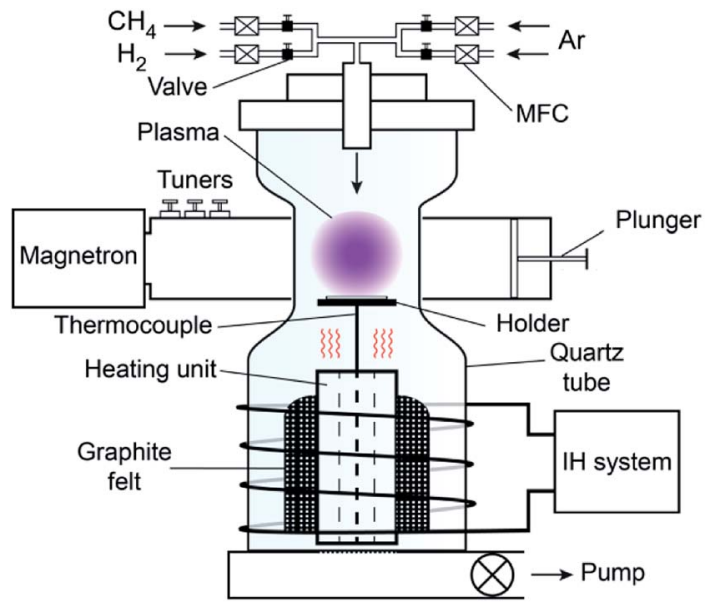

Fig. 1 Schematic diagram of the IH-MPCVD system.

(S08-6093, Daiichi Kiden, Tokyo, Japan, $6 \mathrm{kHz}, 12.5 \mathrm{~kW}$ ), and a vacuum system. A hollow graphite cylinder heated by the induction heating device was set below the substrate holder as heating unit surrounded by a graphite felt. The substrate holder was supported by an alumina tube within a K-type thermocouple. The temperature signals of thermocouple were fed back to the IH-system.

Single-crystalline silicon $\langle 100\rangle$ wafers with dimensions of $10.0 \times 15.0 \times 0.5 \mathrm{~mm}$ were used as substrates. To enhance nucleation, the Si substrates were scratched via ultrasonic bath in acetone with diamond powders (10-40 $\mu \mathrm{m})$ for 1 hour. The scratched substrates were taken ultrasonic cleaning in deionized water, and then dried in a $\mathrm{N}_{2}$ flow.

The substrates were preheated at $873 \mathrm{~K}$ in 30 minutes after quartz chamber was evacuated to $10^{-1} \mathrm{~Pa}$. The input gas flow rate of $\mathrm{H}_{2}\left(f_{\mathrm{h}}\right)$ was $400 \mathrm{sccm}$. The flow rate of $\mathrm{CH}_{4}\left(f_{\mathrm{c}}\right)$ was varied from 1 to $10 \mathrm{sccm}$. The total pressure $\left(P_{\text {tot }}\right)$ and the microwave power $\left(p_{\mathrm{w}}\right)$ were $4 \mathrm{kPa}$ and $900 \mathrm{~W}$, respectively. The induction heating power $\left(p_{\mathrm{h}}\right)$ of the intermediate frequency induction heating device was self-adjusted from 0 to $12.5 \mathrm{~kW}$, according to the substrate temperature assessed by thermocouple. Thus, the substrate temperatures $\left(T_{\mathrm{sub}}\right)$ were controlled in the range of 923-1123 K. The depositions for all samples were carried out for a total time of $3 \mathrm{~h}$.

Phase identification of the films was obtained by Raman spectra (LabRAM HR Evolution; Horiba, Paris, France) with the excitation of a diode laser $532 \mathrm{~nm}$ in wavelength. Crystalline phases were examined by X-ray diffraction with $\mathrm{Cu}-\mathrm{K} \alpha$ radiation (XRD; Ultima III, Rigaku, Tokyo, Japan, at $40 \mathrm{kV}$ and $40 \mathrm{~mA}$ ). A field-emission scanning electron microscope (SEM; Quanta250, FEI, Houston, TX, at $20 \mathrm{kV}$ ) was used to observe the film thickness and microstructure. The surficial roughness was analyzed by atomic force microscopy (AFM; Multimode 8-HR, Bruker, Santa Barbara, USA). The hardness and young's modulus were analyzed by a MTS Nano-indenter (Agilent Technologies G200, California, USA).

\section{Results and discussion}

Fig. 2(a)-(e) shows the surficial morphology of diamond films grown at $T_{\text {sub }}=1073 \mathrm{~K}$ and various $\mathrm{CH}_{4} / \mathrm{H}_{2}$ ratio $\left(\eta_{\mathrm{c}}\right)$ ranging from 0.5 to 2.5 vol\%. At $\eta_{\mathrm{c}}=0.5 \%$, the film consisted of regulated quadrate grains with average size of $0.36 \mu \mathrm{m}$ [Fig. 2(a)]. At $\eta_{\mathrm{c}}=1.0 \%$ and $1.5 \%$, the films exhibited faceted columnar structure with average grain size of $0.34 \mu \mathrm{m}$ and $0.44 \mu \mathrm{m}$, respectively [Fig. $2(\mathrm{~b}$ and $\mathrm{c})$ ]. At $\eta_{\mathrm{c}}=2.0 \%$, the grains were coated by nanoparticles [Fig. 2(d)]. By increasing $\eta_{\mathrm{c}}$ to $2.5 \%$, the films showed dense spherical "cauliflower-like" morphology [Fig. 2(e)]. The cauliflower-like structures was also observed by Hemawan ${ }^{\mathbf{1 1}}$ via AP-MPCVD. They explained that the formation of spherical and polygonal shapes in the atmospheric pressure MPCVD was due to surface diffusion and condensation from vapor phase. ${ }^{12}$ The cross-sectional view [Fig. $\left.2(\mathrm{f}-\mathrm{j})\right]$ revealed the film thickness reached the maximum at $\eta_{\mathrm{c}}=1.5 \%$.

The minimum roughness $\left(R_{\mathrm{ms}}\right)$ of film surface is approximately $23.4 \mathrm{~nm}$ at $\eta_{\mathrm{c}}=2.0-2.5 \%$, as shown in Fig. 3, which is much smaller than that obtained at low $\eta_{\mathrm{c}}=1.0 \%$ (about 80 $\mathrm{nm}$ ). Fig. 4 shows the XRD patterns of the deposit, the peaks corresponding to diamond $(111)$ at $43.9^{\circ}(2 \theta)$ were only detected for all the specimens, indicating (111) orientation. In terms of

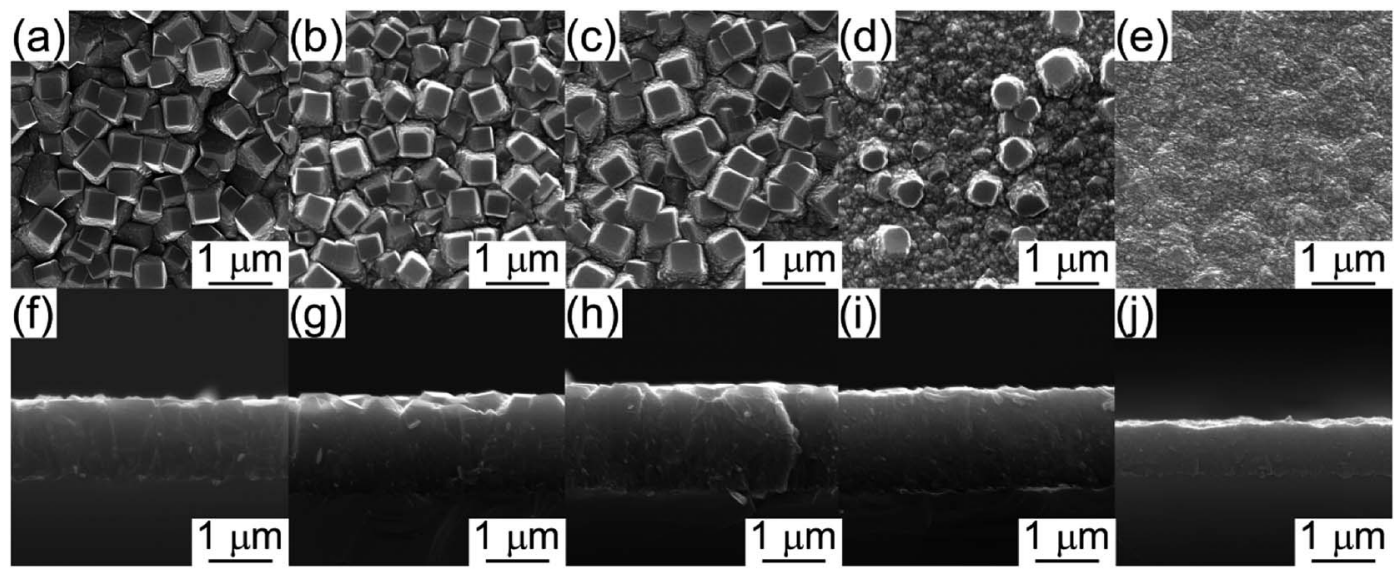

Fig. 2 Surficial and cross-sectional SEM image of diamond films deposited at $T_{\text {sub }}=1073 \mathrm{~K}$ and various $\mathrm{CH}_{4} / \mathrm{H}_{2}$ ratio $\left(\eta_{\mathrm{c}}\right):(\mathrm{a}$ and f) 0.5 , (b and g) 1.0, (c and h) 1.5, (d and i) 2.0 and (e and j) 2.5 vol\%. 


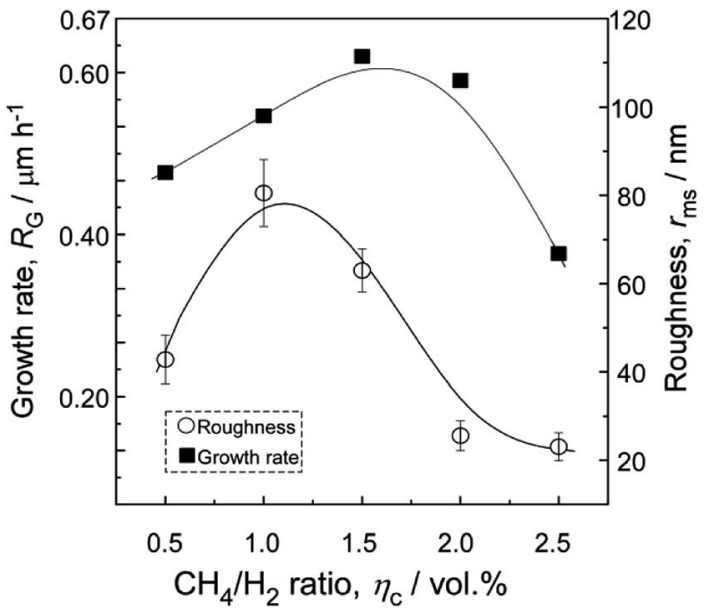

Fig. 3 Effect of $\eta_{\mathrm{c}}$ on the surface roughness and growth rate of the diamond films at $T_{\text {sub }}=1073 \mathrm{~K}$.

carbon chemistry in the plasma discharge, relatively higher $\eta_{\mathrm{c}}$ results in rich $\left[\mathrm{C}_{x} \mathrm{H}_{y}\right]$ and other methyl radicals which are important for diamond nucleation. These species enhance the re-nucleation process of diamond, as well as the $\mathrm{sp}^{2}$ hybridized carbon formation..$^{13}$ By reducing the $\mathrm{CH}_{4}$ fraction in the plasma, the $\mathrm{C}_{x} \mathrm{H}_{y}$ species decreased, especially the species with $x>3$ (e.g. $\left.\left[\mathrm{C}_{4} \mathrm{H}_{2}\right],\left[\mathrm{C}_{3} \mathrm{H}_{2}\right]\right)$. As a result, the hydrocarbon species with $x \leq 2$ incorporates into the lattice by forming a $\mathrm{C}-\mathrm{C}$ bond to an atom that belongs to a lower-lying terrace, and weaken the nucleation of $\mathrm{sp}^{2}$ hybridized carbon phase. ${ }^{5}$ Therefore, well-faceted diamond prefers relatively lower $\eta_{\mathrm{c}}$ under a constant microwave power in this study.

Fig. 5 shows the cross-sectional and surficial SEM image of diamond films deposited at various $T_{\text {sub }}$ ranging from 923 to $1123 \mathrm{~K}$ at $\eta_{\mathrm{c}}=0.5 \%$. The cross-sectional images revealed that the film thickness varied from 0.5 to $1.9 \mu \mathrm{m}$ [Fig. 5(f)-(j)]. Namely, in this range, the substrate temperature caused an enhancement in diamond growth rate $\left(R_{\mathrm{G}}\right)$.

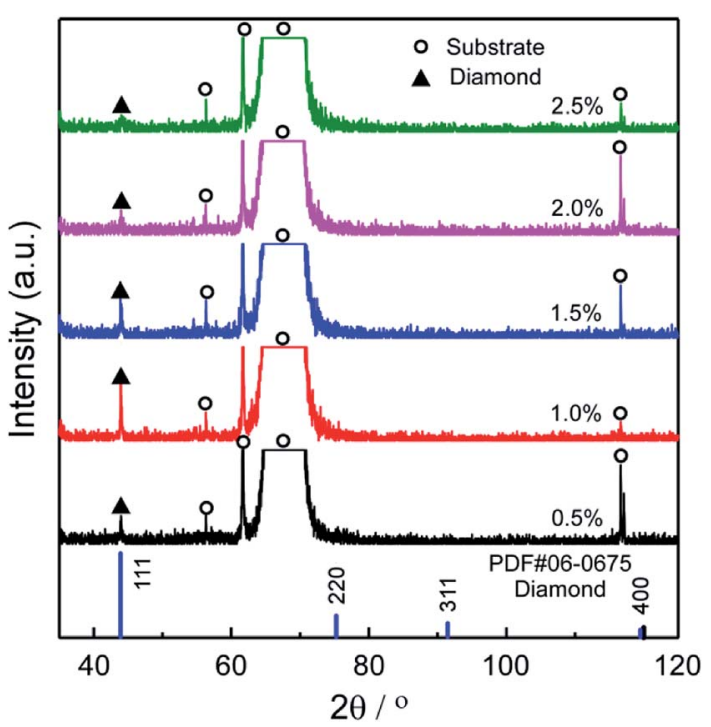

Fig. 4 XRD patterns of films deposited at $T_{\text {sub }}=1073 \mathrm{~K}$ and various $\eta_{\mathrm{C}}$.
The magnified details of the samples are given in Fig. 5(a)(e), pyramidal micrometric diamond crystals are visible at the terminal surface, both triangular and square facets corresponding to $\{111\}$ and $\{100\}$ lattice plane were observed. The quadrate planes of $\{100\}$ facets appear at all the samples [Fig. 5(a-e)], while the triangular $\{111\}$ facets present at lower temperature [Fig. $5(\mathrm{a}-\mathrm{c})]$. Area ratio of square and triangular planes obviously grew larger with the increasing of $T_{\text {sub }}(923-$ $1073 \mathrm{~K})$, owing to the different growth ratio $\left(R_{h k l}\right)$ of each plane. According to the Wulff configurations,${ }^{14}$ the slowest growing plane would be the one survive in growing diamond particles, and vice versa, the fastest one would disappear completely. Fig. 5(k-n) illustrate the Wulff configurations for diamond deposited at 923, 973, 1023, $1073 \mathrm{~K}$ respectively as a function of the facet growth ratio of $\{100\}$ over $\{111\}$, defined as parameter $\alpha$. The XRD result of this group sample shows that only diamond (111) at $43.9^{\circ}(2 \theta)$ was detected, indicating (111) orientation.

Wild et al. ${ }^{15}$ introduced the growth parameter $\alpha$ which relates the growth rates along different crystal axes; $\langle 111\rangle$ direction would be the fastest growing direction when $\alpha$ is 1 , and the growth morphology would be cubic; when $\alpha$ is 3 , the fastest growing direction would be $\langle 100\rangle$ direction, and the growth morphology would be octahedron. For example, in addition to the twinning process, the CVD diamond would show truncated octahedron morphology in various scale when $\alpha$ is 1.5. In this study, for diamond deposited at $923-1023 \mathrm{~K}$ [Fig. $5(\mathrm{k})-(\mathrm{m})], \alpha$ is 1 to 3 , and $\alpha$ increase with $T_{\text {sub }}$. For diamond deposited at 1073 $\mathrm{K}$ [Fig. $5(\mathrm{n})$ ], $\alpha$ is close to 3 . In conclusion, the parameter $\alpha$ shows a negative relation with the rising $T_{\text {sub }}$, indicating that the $R_{111}$ increases faster than the $R_{100}$ with the $T_{\text {sub }}$ [Fig. 5(a)(d)].

Others have reported the order of calculated energy barriers of different diamond surface planes (i.e. $\{110\}<\{111\}<$ $\{100\}){ }^{16-19}$ Namely, $\{100\}$ surface planes are the most stable facets of CVD diamond grains among H-rich plasma, and the hydrogen abstraction process on $\{111\}$ facets run faster than those on $\{100\}$ facets. The whole growth process of CVD diamond would speed up with increasing $T_{\text {sub, }}$ as a result, the growth rate of $\langle 111\rangle$ direction would be much faster than $\langle 100\rangle$ direction.

Fig. 6 shows the surficial roughness increased with increasing $T_{\text {sub }}$ except one grown at $1123 \mathrm{~K}$ and accompanied by an increasing of film thickness and grain size. These findings are understandable because the diamond film presents a columnar crystal cross-section in Fig. 5, which indicates that the evolution of grain size follows the van der Drift mode ${ }^{14}$ with columnar structure. The diagram in Fig. 6 depicts the evolution of film thickness and surficial roughness in this temperature series. ${ }^{6,20,21}$ The surficial roughness and film thickness showed a positive correlation, except one grown at $1123 \mathrm{~K}$. The AFM topographies suggest that the spherical carbon species may present at higher $T_{\mathrm{sub}}$, and these amorphous little particles prefer to generate at the ravines between the micro-crystalline grains, which slightly decrease the roughness.

Fig. 7 shows the dependence of the $R_{\mathrm{G}}$ on the $T_{\mathrm{sub}}$. The $R_{\mathrm{G}}$ of diamond films, with a good quality, is at an intermediate level. 


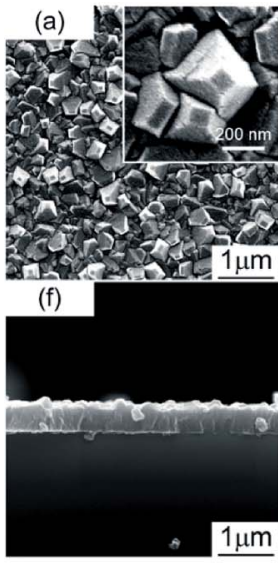

(k)

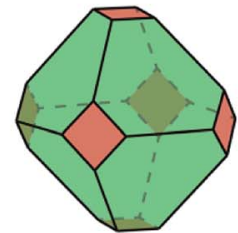

(b)
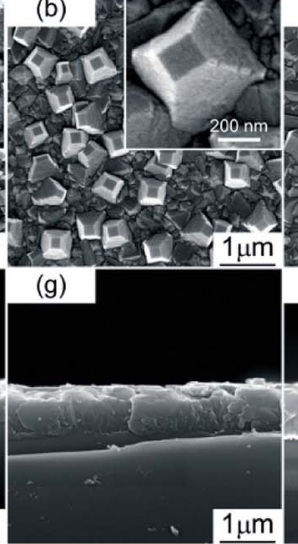

(I)

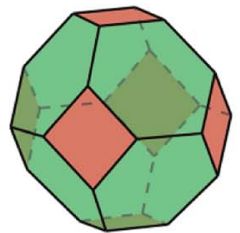

(c)
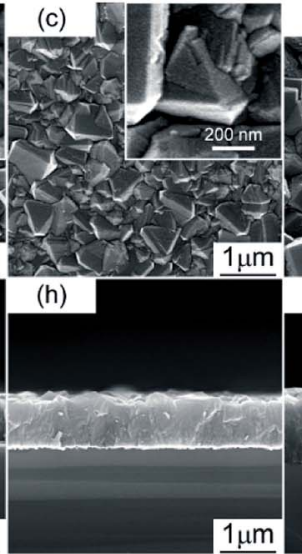

(m)

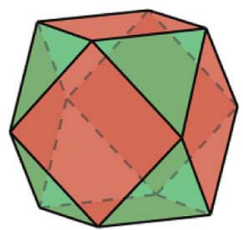

(d)

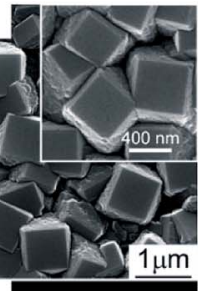

(e)
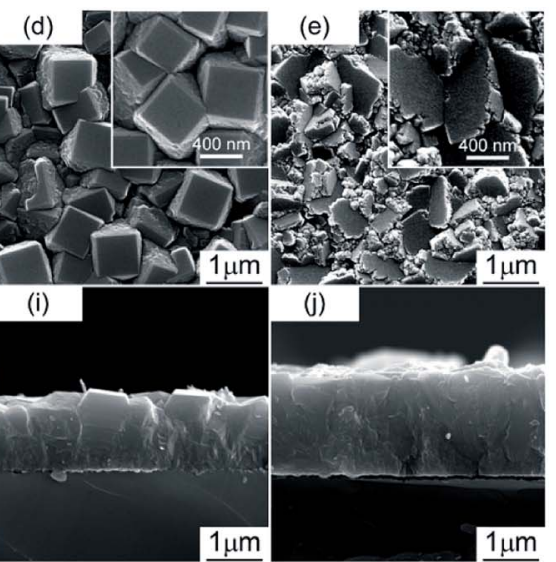

(n)

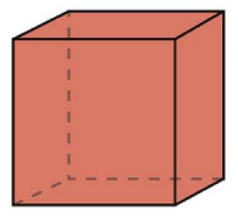

$\{111\}$ facets

$\{100\}$ facets

Fig. 5 Cross-sectional and surficial SEM image of diamond films deposited at $T_{\text {sub }}=923$ (a and f), 973 (b and g), 1023 (c and h), 1073 (d and i) and $1123 \mathrm{~K}(\mathrm{e}$ and $\mathrm{j})$ and $\eta_{\mathrm{c}}=0.5 \mathrm{vol} \%$. $(\mathrm{k}-\mathrm{n})$ is the Wulff configurations for diamond as a function of the facet growth ratio of $\{100\}$ over $\{111\}$.

The activation energy of $53 \mathrm{~kJ} \mathrm{~mol}^{-1}$ calculated by Arrhenius plot of the $R_{\mathrm{G}}$ versus a reciprocal $T_{\text {sub }}$. The result indicates that diamond growth process is limited by temperature controlled chemical process, which under a constant microwave power. Stiegler et al. ${ }^{25}$ investigated the growth kinetics of diamond films deposited at low substrate temperatures (673-873 K), and they supposed that increasing $R_{\mathrm{G}}$ is most probably caused by the removal of surface bonded hydrogen atoms from the carbon sites. Thus, we induced that with a higher temperature, the removal of surface bonded hydrogen atoms would get easier, and then caused a higher $R_{\mathrm{G}}$.

Fig. 8 indicates the Raman spectra for the films deposited at different $T_{\text {sub }}$. In all samples, a sharp peak has been observed at

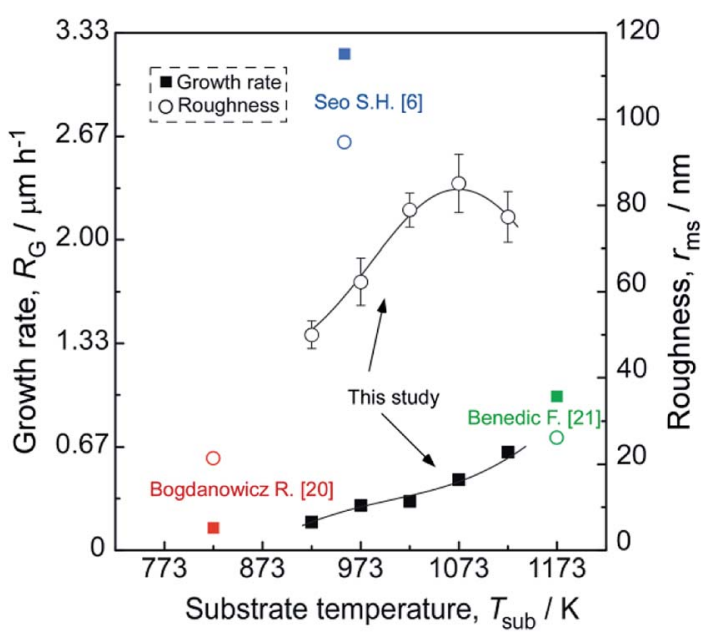

Fig. 6 Evolution of the surface roughness and growth rate of the diamond films synthesized at various $T_{\text {sub }}, \eta_{\mathrm{c}}=0.5 \mathrm{vol} \%$.
$1332 \mathrm{~cm}^{-1}$, which corresponds to the zone center of $T_{2 g}$ symmetry of diamond. The other obvious characteristic peak occurs at $1575 \mathrm{~cm}^{-1}$ presenting the zone center $\mathrm{E}_{2 \mathrm{~g}}$ mode of crystalline graphite, and it is usually designated as the " $G$ " band for graphite. Besides, in micro-crystalline graphite, an additional sharp peak should appear at a wave number of $1350 \mathrm{~cm}^{-1}$ in the Raman spectra, which represents a zone-edge $\mathrm{A}_{1 \mathrm{~g}}$ mode, named "D" band..$^{27,28}$ However, the peak of " $D$ " band, which close to the sharp diamond $\mathrm{T}_{2 \mathrm{~g}}$ peak, was absent from all the Raman spectra in Fig. 8. Namely, there is little crystalline graphite in these diamond films. In addition to the diamond and graphite, for all the other kinds of amorphous and nanocrystalline carbon species, the Raman spectra typically shows a shoulder and broad "G" band centered around $1550 \mathrm{~cm}^{-1}$ and a "D" band centered at $1375 \mathrm{~cm}^{-1} \cdot{ }^{29}$ The intensity of sharp diamond peak is much higher than the other peaks, which indicates the higher proportion of $\mathrm{sp}^{3}$ carbon atoms in these samples. With increasing $T_{\text {sub }}$, the related intensity of broad G peak increases, and the " $\mathrm{G}$ " band slightly moves up to $1580 \mathrm{~cm}^{-1}$. The slight shift in the broad " $\mathrm{G}$ " band frequency is consistent with an increase of amorphous component which produced from the carbon soot formation..$^{30}$ The downshift and broadening of the diamond peak in nanocrystalline diamond also have previously been observed and explained by quantum confinement effect. ${ }^{31}$ The phase purity is evaluated by the $\mathrm{sp}^{3} /$ $\mathrm{sp}^{2}$ ratio $(r)$ from the Raman spectra and expressed as eqn (1), ${ }^{32}$

$$
r=\frac{75 \times I_{\mathrm{d}}}{75 \times I_{\mathrm{d}}+\sum_{\mathrm{nd}} I_{\mathrm{nd}}} \times 100 \%
$$

where, $I_{\mathrm{d}}$ is the Raman diamond peak area centered at 1332 $\mathrm{cm}^{-1}$ and $\sum_{\mathrm{nd}} I_{\mathrm{nd}}$ is the sum of Raman $\mathrm{sp}^{2}$ phase peak areas. The 


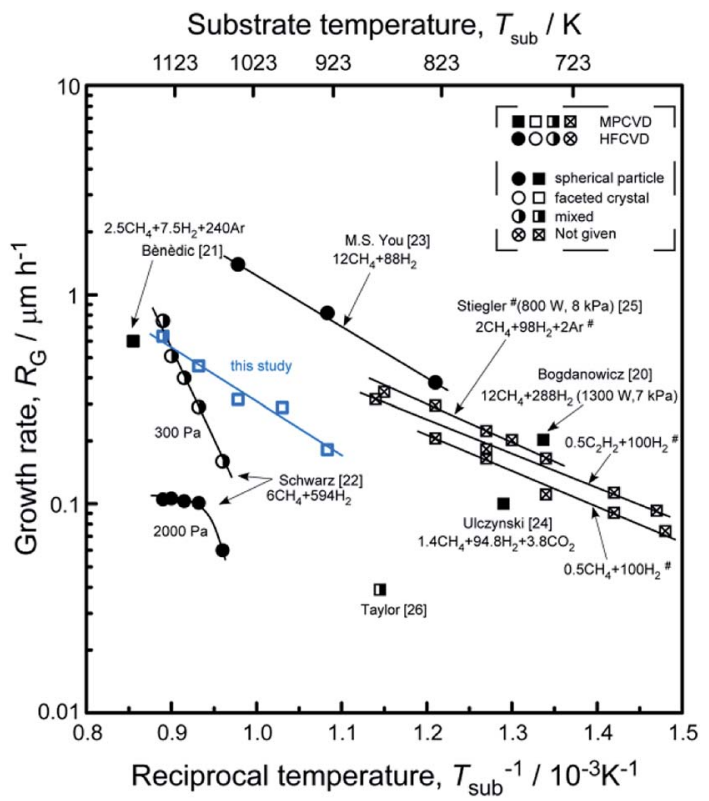

Fig. 7 Effect of $T_{\text {sub }}$ on $R_{\mathrm{G}}, \eta_{\mathrm{c}}=0.5$ vol\%.

factor 75 takes into account the more effective Raman scattering of $\mathrm{sp}^{2}$ structures. ${ }^{33,34}$ The $\mathrm{sp}^{3} / \mathrm{sp}^{2}$ ratio of samples shown in Fig. 8 are various from 93 to $98 \%$. However, it should be noticed that two weak peaks occur at $1140 \mathrm{~cm}^{-1}$ and $1450 \mathrm{~cm}^{-1}$, respectively. Others have reported the two peaks not only appear together, yet they also show quite strong and similar dispersions, while the diamond mode does not. Moreover, Kuzmany et al. ${ }^{35}$ have given a clear proof that these peaks originate from trans-polyacetylene in the grain boundaries by the H-D isotopic substitution result. In Raman features observed here, these two peaks usually occur in the Raman spectra of samples deposited at low temperatures. This is due to the slow growth rate at low $T_{\text {sub}}$, and the re-nucleating process leads to a high nucleation

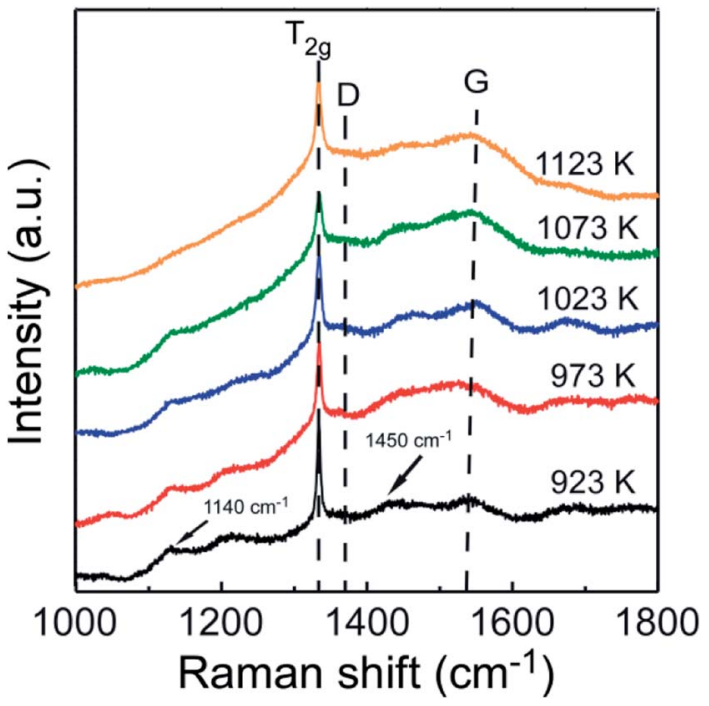

Fig. 8 Raman spectra of the diamond films synthesized at various $T_{\text {sub, }}$ $\eta_{\mathrm{c}}=0.5$ vol\%. density with a large amount of boundaries among little grains, where polyacetylene existed. In order to ensure the quality of diamond films, the $T_{\text {sub }}$ during diamond growth process should not be higher than $1073 \mathrm{~K}$, neither be lower than $973 \mathrm{~K}$ in this study.

As shown in Fig. 9, the surficial morphologies of diamond films can be defined as three categories: the well-faceted crystalline, the spherical structures composited with nanoparticles, and the mixture of both morphologies. At a relative high $T_{\text {sub }}$ $(\geq 1073 \mathrm{~K}),\{100\}$ planes occurred on the film surface. For high $\mathrm{CH}_{4} / \mathrm{H}_{2}$ ratio $\left(\eta_{\mathrm{c}} \geq 2.0 \%\right)$ and low $T_{\text {sub }}(\leq 973 \mathrm{~K})$, more spherical nanoparticles were formed instead of crystalline structure.

In order to follow the mechanical properties, a nanoindentation technique was performed. Fig. 10 demonstrates the relationships between average hardness $\left(H_{\mathrm{a}}\right)$, Young's modulus $(E)$ and $T_{\text {sub }}$. The $H_{\mathrm{a}}$ and $E$ were calculated from the correlation between load/unload and displacement (i.e., displacement-load curves not shown here). The theoretical value of Poisson's coefficient $(\nu)$ used for calculating the Young's modulus was 0.20 , according to the Poisson's ratio of CVD polycrystalline diamond. ${ }^{36}$ The results reveal that the $H_{\mathrm{a}}$ and $E$ of films increased with $T_{\text {sub }}$ when it ranged in 923-1073 K; the maximum $H_{\mathrm{a}}$ and $E$ reached $84 \mathrm{GPa}$ at $973 \mathrm{~K}$ and $642 \mathrm{GPa}$ at $1023 \mathrm{~K}$, respectively. The value is twice as much as regular NCD films by MPCVD,${ }^{37}$ much hard than those deposited in argon plasma. ${ }^{38}$ Exceptionally, both $H_{\mathrm{a}}$ and $E$ decreased marginally when $T_{\text {sub }}$ beyond $1123 \mathrm{~K}$. This anomaly may result from nondiamond phases generated among diamond crystals, confirmed by SEM, AFM and Raman spectra.

For most applications of diamond films, such as wearresistant coatings, heatsinks, MEMS and surface acoustic wave devices, a high $\mathrm{sp}^{3}$ component, a high hardness and a low surface roughness are crucial and favorable, but are hard to possess simultaneously. For example, diamond film with an extreme smooth surface always shows a poor mechanical property and low $\mathrm{sp}^{3} / \mathrm{sp}^{2}$ ratio. To evaluate the quality of different diamond films by microstructure and mechanical behaviors, we proposed a parameter, quality factor $(Q)$, as a formula model:

$$
Q=\frac{r^{a} \times H^{b}}{R_{\mathrm{ms}}{ }^{c}}
$$

where, $r$ refers to $\mathrm{sp}^{3} / \mathrm{sp}^{2}$ ratio, $H$ refers to hardness, $R_{\mathrm{ms}}$ refers to surface roughness, $a, b, c$ are exponential parameters, $Q$ refers to the quality factor of diamond films, the higher the value of $Q$, the better the quality of diamond films. This formula model is reasonable from a qualitative point of view, because a high $r$ and $H$, and a low $R_{\mathrm{ms}}$ result in a high value of $Q$, which means a high quality of diamond film, accordingly, a high sp ${ }^{3}$ component and hardness, and a low surface roughness are favourable for most applications of diamond films. Here, values of $a, b, c$ were provided as $4,4,0.5$ respectively, based on the researches in this study after fitting.

Fig. 11 shows $Q$ of DLC, ${ }^{39} \mathrm{NCD}^{40}$ and diamond ${ }^{41}$ materials fabricated at different conditions $\left(p_{\mathrm{w}} \times \eta_{\mathrm{c}} \times P_{\text {tot }}\right)$, in which DLC, NCD and diamond area are classified by $Q$ in the order of $1 \times$ $10^{4}, 1 \times 10^{5}$ and $1 \times 10^{6}$, respectively. Through comparing the 


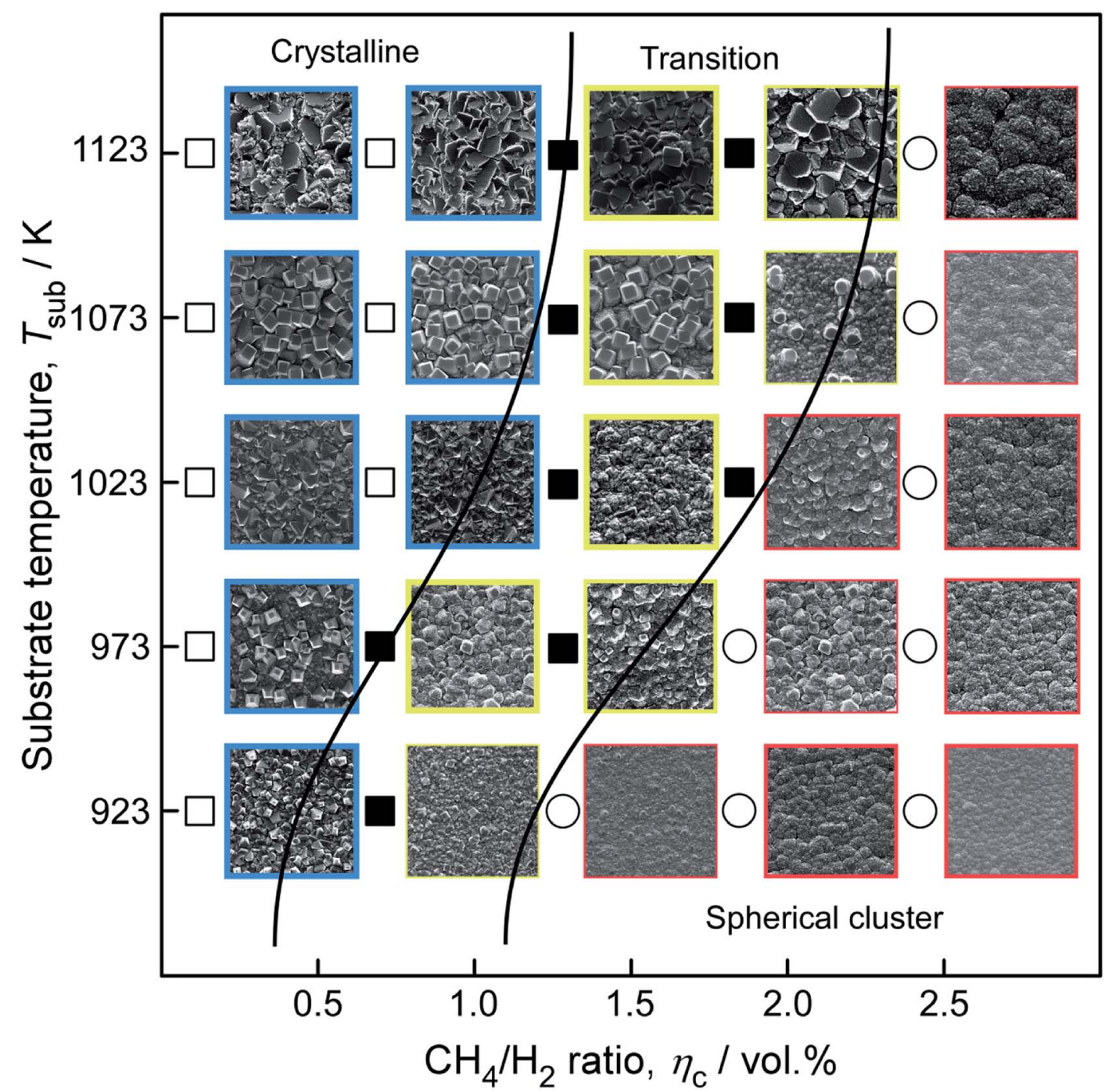

Fig. 9 Coupling effects of $\eta_{\mathrm{c}}$ and $T_{\text {sub }}$ on structure of diamond films.

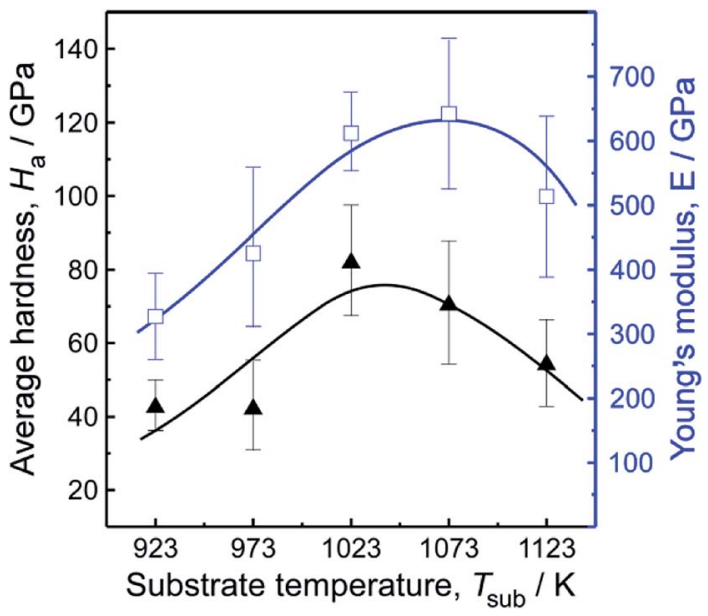

Fig. 10 Average hardness $\left(H_{\mathrm{a}}\right)$ and Young's modulus $(E)$ of samples fabricated with various $T_{\text {sub }}, \eta_{\mathrm{c}}=0.5$ vol\%. values of $Q$, we could judge the quality of the diamond related materials more visually. Most specimens fabricated in this study are in the diamond area and NCD area, which demonstrates that with a relatively good quality, the diamond films in the present study would have a good performance in wearresistant coatings, heatsinks, MEMS and surface acoustic wave devices.

The residual stress $(\sigma)$, as a function of various $T_{\text {sub }}$ at $\eta_{\mathrm{c}}=0.5 \%$ and various $\eta_{\mathrm{c}}$ at $1073 \mathrm{~K}$ was calculated by eqn (3). ${ }^{42}$

$$
\sigma=-0.567\left(\nu-\nu_{0}\right)(\mathrm{GPa})
$$

where $\nu_{0}=1332 \mathrm{~cm}^{-1}, \nu$ is the observed Raman shift corresponding to diamond peak, $\sigma<0$ and $\sigma>0$ correspond to the compressive and tensile stress, respectively. The residual stress generally includes intrinsic stress and thermal stress. The thermal stress is due to different thermal expansion coefficients of the film and substrate. Peng et $a .^{43}$ demonstrated that the intrinsic compressive stress of diamond films was mainly caused by impurities such as $\mathrm{sp}^{2}$ bonded carbon and hydrogen, 


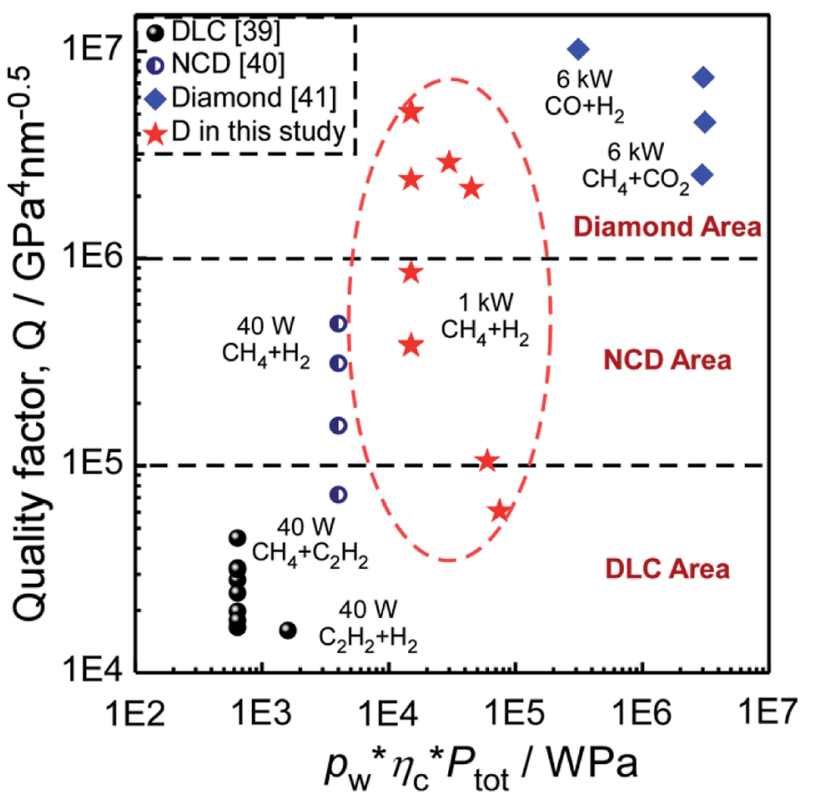

Fig. 11 Quality factor (Q) of DLC, NCD and Diamond materials fabricated at different conditions $\left(p_{\mathrm{w}} \times \eta_{\mathrm{c}} \times P_{\text {tot }}\right)$.

and tensile stress was caused by defects such as excess vacancies, which mainly formed from $\mathrm{sp}^{2}$ carbon after etching by atomic hydrogen, and grain boundaries. ${ }^{44}$ Besides, the thicker of diamond film, the higher of the compressive stress. ${ }^{45}$ As shown in Fig. 12, $\sigma$ increased from -1.54 to $-0.79 \mathrm{GPa}$ as $T_{\text {sub }}$ increased from $923 \mathrm{~K}$ to $1073 \mathrm{~K}$, which was ascribed to decreasing $\mathrm{sp}^{2}$ bonded carbon content with $T_{\text {sub }}$. However, a decrease of $\sigma$ was observed at $1123 \mathrm{~K}$ due to the presence of spherical carbon species, and increase of film thickness as evidenced by SEM photograph in Fig. 5(e)-(j). With $\eta_{\mathrm{c}}$ increasing from 0.5 to $2.5 \%, \sigma$ increased from -0.79 to $0.60 \mathrm{GPa}$. Higher $\mathrm{sp}^{2}$ carbon content was formed at higher $\eta_{\mathrm{c}}$, most of which was etched away by atomic hydrogen and then

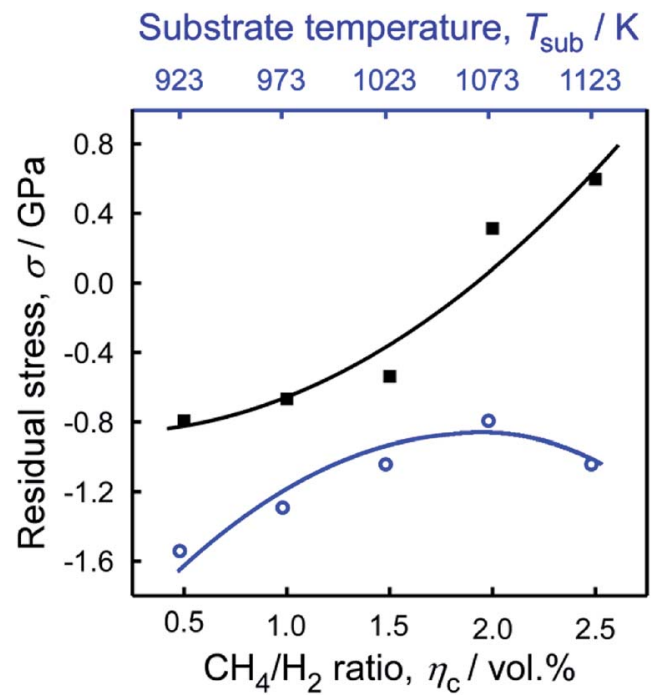

Fig. 12 Residual stress variation with $T_{\text {sub }}\left(\eta_{\mathrm{c}}=0.5 \%\right)$ and $\eta_{\mathrm{c}}\left(T_{\text {sub }}=\right.$ $1073 \mathrm{~K})$. became vacancies. The increasing excess vacancies produced tension stress and caused an increase in residual stress. Furthermore, nanocrystalline diamond preferred to grow at relatively higher $\eta_{\mathrm{c}}$, as evidenced by SEM photograph in Fig. 2(d and e), resulting in an increase in density of grain boundaries, thus, $\sigma$ increased.

\section{Conclusions}

To improve the thermal control process of MPCVD technique, we have explored an intermediate-frequency induction heated MPCVD (IH-MPCVD) system. Coupling effects of $T_{\text {sub }}$ (923-1123 $\mathrm{K})$ and $\eta_{\mathrm{c}}(0.5-2 \mathrm{vol} \%)$ on structure of diamond films shows that the surficial morphologies of diamond films can be defined as three categories: the well-faceted crystalline, the spherical structures composited with nanoparticles, and the mixture of both morphologies. Higher $\eta_{\mathrm{c}}(2.5 \mathrm{vol} \%)$ enhances the renucleation process which leads to a smooth surface, yet lower $\eta_{\mathrm{c}}(0.5 \mathrm{vol} \%)$ results in better crystalline quality of diamond films. At $\eta_{\mathrm{c}}=0.5 \mathrm{vol} \%$, the morphology transformed from pyramid to quadrate column with $T_{\text {sub }}$ increasing from 923 to $1073 \mathrm{~K}$, besides, the maximum hardness $\left(H_{\mathrm{a}}\right)$ and Young's modulus $(E)$ was $84 \mathrm{GPa}$ and $642 \mathrm{GPa}$, at $T_{\text {sub }}=1023,1073 \mathrm{~K}$, respectively. The residual stress increased from -1.54 to $-0.79 \mathrm{GPa}$ with $T_{\mathrm{sub}}$, at $\eta_{\mathrm{c}}=0.5 \mathrm{vol} \%$, and then decreased, while at $1073 \mathrm{~K}$, it increased with $\eta_{\mathrm{c}}$ and reached to $0.60 \mathrm{GPa}$ at $\eta_{\mathrm{c}}=$ $2.5 \mathrm{vol} \%$.

\section{Conflicts of interest}

There are no conflicts to declare.

\section{Acknowledgements}

This work was supported by the National Natural Science Foundation of China (No. 51372188, and 51521001) and by the 111 Project (B13035). This research was also supported by the International Science \& Technology Cooperation Program of China (2014DFA53090) and the Natural Science Foundation of Hubei Province, China (2016CFA006), and the National Key Research and Development Program of China (2017YFB0310400), and the Fundamental Research Funds for the Central Universities (WUT: 2017II43GX, 2017III032, 2017YB004, 2018III016), and Science Challenge Project (No. TZ2016001).

\section{References}

1 F. A. Almeida, E. Salgueiredo, F. J. Oliveira, R. F. Silva, D. L. Baptista, S. B. Peripolli and C. A. Achete, ACS Appl. Mater. Interfaces, 2013, 5, 11725.

2 J. J. Gracio, Q. H. Fan and J. C. Madaleno, J. Phys. D: Appl. Phys., 2010, 43, 374017.

3 R. S. Balmer, J. R. Brandon, S. L. Clewes, H. K. Dhillon, J. M. Dodson, I. Friel, P. N. Inglis, T. D. Madgwick, M. L. Markham, T. P. Mollart, N. Perkins, G. a. Scarsbrook, 
D. J. Twitchen, a. J. Whitehead, J. J. Wilman and S. M. Woollard, J. Phys.: Condens. Matter, 2009, 21, 364221.

4 A. Gicquel, K. Hassouni, F. Silva and J. Achard, Curr. Appl. Phys., 2001, 1, 479.

5 M. Eckert, E. Neyts and A. Bogaerts, Cryst. Growth Des., 2010, 10, 4123.

6 S. H. Seo, W. C. Shin and J. S. Park, Thin Solid Films, 2002, 416, 190.

7 W. C. Shih, M. J. Wang and I. Nan Lin, Diamond Relat. Mater., 2008, 17, 390.

8 Y. Q. Fu, L. Garcia-Gancedo, H. F. Pang, S. Porro, Y. W. Gu, J. K. Luo, X. T. Zu, F. Placido, J. I. B. Wilson, A. J. Flewitt and W. I. Milne, Biomicrofluidics, 2012, 6, 024105.

9 S. A. Catledge, J. Borham, Y. K. Vohra, W. R. Lacefield, J. E. Lemons, S. A. Catledge, J. Borham and Y. K. Vohra, J. Appl. Phys., 2002, 91, 5347.

10 O. A. Williams, M. Daenen, J. D'Haen, K. Haenen, J. Maes, V. V Moshchalkov, M. Nesládek and D. M. Gruen, Diamond Relat. Mater., 2006, 15, 654.

11 K. W. Hemawan, H. Gou, R. J. Hemley, K. W. Hemawan, H. Gou and R. J. Hemley, Appl. Phys. Lett., 2015, 107, 181901. 12 J. Kim, H. Sakakita, H. Ohsaki and M. Katsurai, Jpn. J. Appl. Phys., 2015, 54, 01AA02.

13 H. J. Lee, K. S. Lee, J. M. Cho, T. S. Lee, I. Kim, D. S. Jeong and W. S. Lee, ACS Appl. Mater. Interfaces, 2013, 5, 11631.

14 A. Van der Drift, Philips Res. Rep., 1967, 22, 267.

15 C. Wild, R. Kohl, N. Herres, W. Müller-Sebert and P. Koidl, Diamond Relat. Mater., 1994, 3, 373.

16 J. Bühler and Y. Prior, J. Cryst. Growth, 2000, 209, 779.

17 Y. Zou and K. Larsson, J. Phys. Chem. C, 2016, 120, 10658.

18 K. E. Spear and J. P. Dismukes, in Synthetic Diamond, Wiley, New York, 1994, p. 663.

19 B. T. Van Regemorter and K. Larsson, Chem. Vap. Deposition, 2008, 224.

20 R. Bogdanowicz, M. Sobaszek, J. Ryl, M. Gnyba, M. Ficek, Ł. Gołuński, W. J. Bock, M. Śmietana and K. Darowicki, Diamond Relat. Mater., 2015, 55, 52.

21 F. Bénédic, M. B. Assouar, F. Mohasseb, O. Elmazria, P. Alnot and A. Gicquel, Diamond Relat. Mater., 2004, 13, 347.

22 S. Schwarz, S. M. Rosiwal, M. Frank, D. Breidt and R. F. Singer, Diamond Relat. Mater., 2002, 11, 589.

23 M. S. You, F. C. N. Hong, Y. R. Jeng and S. M. Huang, Diamond Relat. Mater., 2009, 18, 155.
24 M. J. Ulczynski, B. Wright and D. K. Reinhard, Diamond Relat. Mater., 1998, 7, 1639.

25 J. Stiegler, T. Lang, Y. Von Kaenel, J. Michler, E. Blank, J. Stiegler, T. Lang, Y. Von Kaenel, J. Michler and E. Blank, Appl. Phys. Lett., 2014, 173, 88.

26 A. Taylor, L. Fekete, P. Hubík, A. Jäger, P. Janíček, V. Mortet, J. Mistrík and J. Vacík, Diamond Relat. Mater., 2014, 47, 27.

27 P. K. Chu and L. Li, Mater. Chem. Phys., 2006, 96, 253.

28 T. S. Yang, J. Y. Lai, C. L. Cheng and M. S. Wong, Diamond Relat. Mater., 2001, 10, 2161.

29 S. Ray, A. R. Middya and A. K. Barua, Jpn. J. Appl. Phys., 1993, 32, L1559.

30 M. A. Pimenta, G. Dresselhaus, M. S. Dresselhaus, L. G. Cancado, A. Jorio and R. Saito, Phys. Chem. Chem. Phys., 2007, 9, 1276.

31 S. Osswald, V. N. Mochalin, M. Havel, G. Yushin and Y. Gogotsi, Phys. Rev. B, 2009, 80, 75419.

32 F. Silva, A. Gicquel, A. Tardieu, P. Cledat and T. Chauveau, Diamond Relat. Mater., 1996, 5, 338.

33 J. R. Moro, J. Mater. Sci., 2007, 42, 7331.

34 R. E. Shroder, R. J. Nemanich and J. T. Glass, Phys. Rev. B, 1990, 41, 3738.

35 H. Kuzmany, R. Pfeiffer, N. Salk and B. Günther, Carbon, 2004, 42, 911.

36 C. A. Klein and G. F. Cardinale, Diamond Relat. Mater., 1993, 2, 918.

37 W. Kulisch, C. Popov, V. Vorlicek, P. N. Gibson and G. Favaro, Thin Solid Films, 2006, 515, 1005.

38 Y. Wubao, K. Xiang, Y. Size and D. Xiaofeng, Vacuum, 2003, 68, 49.

39 J. S. Hsu, S. S. Tzeng and Y. J. Wu, Vacuum, 2008, 83, 622.

40 T. Sharda, T. Soga, T. Jimbo and M. Umeno, J. Nanosci. Nanotechnol., 2001, 1, 287.

41 M. I. De Barros, L. Vandenbulcke, L. Chinsky, D. Rats and J. Von Stebut, Diamond Relat. Mater., 2001, 10, 337.

42 J. R. Moro, J. Mater. Sci., 2007, 42, 7331.

43 X. L. Peng, Y. C. Tsui and T. W. Clyne, Diamond Relat. Mater., 1997, 6, 1612.

44 H. Windischmann and K. J. Gray, Diamond Relat. Mater., 1995, 4, 837.

45 M. J. Ulczynski, B. Wright and D. K. Reinhard, Diamond Relat. Mater., 1998, 7, 1639. 